\title{
Quassinoid Agent
}

National Cancer Institute

\section{Source}

National Cancer Institute. Quassinoid Agent. NCI Thesaurus. Code C1974.

A group of phytochemicals isolated from several species of the plant family

Simaroubaceae with potential antineoplastic activity. Quassinoid agents also exhibit antimalarial, antiprotozoal and antiproliferative activities. ( $\mathrm{NCl04)}$ 